\title{
Therapeutic Modalities for Management of Hemolysis in Pediatric Extracorporeal Membrane Oxygenation (ECMO)
}

\author{
Aqsa Shakoor, $\mathrm{MD}^{1}$, Ariela Zenilman, $\mathrm{MD}^{1}$, Jennifer DeFazio, $\mathrm{MD}^{1}$, Linda $\mathrm{Li}, \mathrm{MD}^{1}$, Cindy Neunert, $\mathrm{MD}^{2}$, \\ Angela Kadenhe-Chiweshe, $\mathrm{MD}^{1}$ \\ ${ }^{1}$ Department of Surgery, New York - Presbyterian, Columbia University Medical Center, New York, NY, USA \\ ${ }^{2}$ Department of Pediatrics, New York - Presbyterian, Columbia University Medical Center, New York, NY, USA \\ ${ }^{*}$ Correspondence to: Aqsa Shakoor, Department of Surgery, New York - Presbyterian, Columbia University Medical Center, New York, NY, USA; \\ E-mail: as2568@cumc.columbia.edu
}

Received: April 26, 2018; Accepted: April 30, 2018; Published: April 30, 2018;

\section{Introduction}

Hemolysis, defined as a rise in plasma-free hemoglobin ( $\mathrm{pfHb})$, lactate dehydrogenase (LDH), or total bilirubin (TB) is a common complication of extracorporeal life support (ECLS) and results in increased morbidity and mortality. It has an incidence of $7.8-13 \%$ in pediatric patients on extracorporeal membrane oxygenation (ECMO) [1-3]. Contributing factors to hemolysis include presence of thrombi within the circuit, high negative inlet pressure, excessive pump speed and sheer stress on the red blood cells [4-6]. Furthermore, factors related to the oxygenator such as cavitation [7] and pressure changes within the oxygenator $[8,9]$, along with longer duration of ECMO support [10], are also known factors.

The major contributors of morbidity from hemolysis are its byproducts, specifically pfHg. pfHg has been reported to rise by as much as 10-25 fold during ECMO [11] and is known to be cytotoxic to cells leading to tissue hypoxia, and ultimately cell death $[12,13]$. High pfHg levels have been associated with multi-organ failure [12, 14], including direct kidney injury and are predictors of acute renal failure for patients on ECMO $[15,16]$. Furthermore, pfHg consumes vascular nitric oxide, leading to inappropriate vasoconstriction and platelet activation [12], further exacerbating already existing ischemic injury and potential for thrombi formation.

As a result of the above injury, hemolysis can result in increased blood product support, need for renal replacement therapy (RRT), prolonged ECMO, longer ICU and hospital stays, and higher mortality [17-19]. There have been several modifications and refinements to ECMO circuitry to mitigate the risk of hemolysis, but it nevertheless remains a significant source of morbidity $[3,6]$. In this mini-review, we discuss potential therapeutic modalities for management of hemolysis in ECMO.

\section{Exchange Transfusion}

Exchange transfusion (ET) has been an established treatment for neonatal hyperbilirubinemia, immune and non-immune red cell hemolysis, and severe sepsis [20]. The basic principle of an exchange transfusion is to remove the patient's red cells, in pre-determined aliquots while transfusing back equal amounts of donor whole blood. This process not only removes circulating $\mathrm{pfHb}$ and $\mathrm{TB}$ but also draws out these byproducts that are deposited in tissue. Several variations exist in protocols for conducting ET in the neonatal population; including the size of aliquots (single vs double volume exchange) [20], route (peripheral vs. umbilical) [21], and method of exchange (continuous vs. push-pull) [22]. The primary aim of this therapy is remove bilirubin in the serum as well as partially hemolyzed an/or antibody-coated red blood cells. This therapy can be expanded to ECLS patients in an effort to reduce not just TB, but also PFHg to avoid secondary organ injury from hemolysis.

There is very little in the literature regarding ET for ECLS-related hemolysis with the exception of case reports [23]. Access points on the ECMO circuitry can be utilized for the removal and infusion of blood products, negating the need for additional access [23]. Mortality directly attributable to ET is estimated to be approximately $1 \%$ with described complications including cardiac arrhythmias due to acute electrolyte derangements, cardiac arrest, hemodynamic instability, or air embolism [24]. Frequent arterial blood gases (ABGs) should guide the clinician in electrolyte replacement or sweep adjustment to maintain normal physiologic parameters [23].

There is no established consensus or guidelines on bilirubin, PFHg, or LDH threshold or signs of secondary organ for initiation of ET. Currently, the decision to perform ET is based on institutional experiences at the discretion of the ICU/ ECMO teams. Given that the development of complication such as acute kidney injury (AKI) and need for RRT, are associated with worsening outcomes and decreased survival in both adult and pediatric populations [25-27], we argue for earlier implementation of ET prior to development of secondary organ injury.

\section{Plasma Exchange}

Plasma exchange (PE) is performed by selectively removing plasma and replacing with either human serum albumin or fresh frozen plasma, chosen on the basis of the indication for PE and 
pathogenic factors contributing to a patient's specific disease process $[28,29]$. Similar to ET, PE can significantly reduce PFHg and TB and its early use has been shown to prevent acute renal failure [30-33]. Utilization of PE has been reported for severe intravascular hemolysis [34], severe hemolysis during cardiopulmonary bypass [35], antibody mediated rejection after heart transplant on ECMO [36], and thrombocytopenia-associated multi-organ failure on ECMO [37].

Similar to ET, the plasma filtration device can be connected inline to the ECMO circuit [38] with an aim to exchange 1.5-2 times the estimated plasma volume. Complications of PE on ECMO include access malfunction, circuit complications including clotting, hypotension, and/or hypocalcemia [38]. PE can also cause a severe coagulopathy if replacement is with albumin and not FFP. Close monitoring of PT/PTT is needed. A single center study reported that $27.6 \%$ of patients undergoing PE on ECMO, experienced citrateassociated hypocalcemia and $34.2 \%$ developed hypotension [39]. Cortina et al reported 50\% survival to discharge in patients requiring CRRT and ECMO who underwent PE [38]. Despite these findings, the authors concluded that simultaneous ECMO and PE is both tolerable and feasible in children and adults. However, it cannot be emphasized enough that continuous hemodynamic and ABG monitoring still remains essential during the procedure regardless of whether an ET or PE is being performed.

\section{Circuit Exchange}

Prolonged ECMO can also result in ECMO circuit induced fibrinolysis, oxygenator thrombosis, or pump head thrombosis. All of which contribute to development of hemolysis as red cells undergo microangiopathic destruction due to injury from microthrombi [40]. Circuit induced fibrinolysis typically occurs in circuits that are at least one week old with associated laboratory findings of rising D-dimer and decreasing fibrinogen levels with or without abnormal bleeding and increased blood product requirements. Oxygenator thrombosis can manifest as increased transmembrane pressures, visible clots on the pre- or post-oxygenator membrane, and/or decreasing oxygenator function manifesting as low post-oxygenator $\mathrm{PaO}$ 2. Lastly, pump head thrombosis results in a rise in $\mathrm{PFHg}$ and inefficient revolutions per minute (RPM) to flow ratios [40].

Pan et al examined the reason for ECMO circuit changes with respect to PFHg [40]. The most common reasons were clinically significant thrombosis or hemolysis, occurring in 14/27 (52\%) runs requiring an exchange. The authors also found an association between higher PFHg value and CRRT requirements, longer time on ECMO, and higher mortality rates. The decision to perform a circuit exchange is nearly always driven by clinical status of the patient and discussion between the ICU and ECMO teams rather than any singular laboratory value or circuit finding. The obvious risks to undergoing circuit exchange is a transient withdrawal of ECLS support, exposure to new foreign surfaces with risk of activation of the coagulation cascade, and platelet dysfunction [41]. Balancing these risks with ongoing hemolysis should be made on a case by base basis.

\section{Summary}

Hemolysis is a common complication of ECMO therapy, due to its associated morbidities and affect on mortality. Hemolysis may be managed by ET, PE, and/or circuit exchange. However, each of these procedures is accompanied by substantial risks. The patients are typically physiologically frail and have minimal reserve to tolerate accumulating complications, especially those relating to secondary organ injury from hemolysis. There is a paucity of literature on the indications, outcomes, and complications from performing these interventions. Furthermore, there is no data comparing these different approaches. A concerted effort by the medical community is needed to systematically appraise these procedures and to standardize the techniques utilized to perform them in the setting of ECMO in order to minimize their associated risks, while optimizing the benefit.

\section{References}

1. Ichiba S, Bartlett RH (1996) Current status of extracorporeal membrane oxygenation for severe respiratory failure. Artif Organs 20(2): 120-3. [Crossref]

2. Haines NM, Rycus PT, Zwischenberger JB, Bartlett RH, Undar A (2009) Extracorporeal Life Support Registry Report 2008: neonatal and pediatric cardiac cases. ASAIO J 55(1): 111-6.[Crossref]

3. Masalunga C, Cruz M, Porter B, Roseff S, Chui B, Mainali E(2007) Increased hemolysis from saline pre-washing RBCs or centrifugal pumps in neonatal ECMO. $J$ Perinatol 27(6): 380-4.[Crossref]

4. Leverett LB, Hellums JD, Alfrey CP, Lynch EC (1972) Red blood cell damage by shear stress. Biophys 12(3): 257-73. [Crossref]

5. Shimono T, Makinouchi K, Nose Y (1995) Total erythrocyte destruction time: the new index for the hemolytic performance of rotary blood pumps. Artif Organs 19(7): 571-5. [Crossref]

6. Barrett CS, Jaggers JJ, Cook EF, Graham DA, Yarlagadda VV, Teele SA, et al. (2013) Pediatric ECMO outcomes: comparison of centrifugal versus roller blood pumps using propensity score matching. ASAIO J 59(2): 145-51. [Crossref]

7. Wielogorski JW, Cross DE, Nwadike EV (1975) The effects of subatmospheric pressure on the haemolysis of blood. J Biomech 8(5): 321-5. [Crossref]

8. Williams DC, Turi JL, Hornik CP, Bonadonna DK, Williford WL, Walczak RJ, et al. (2015) Circuit oxygenator contributes to extracorporeal membrane oxygenationinduced hemolysis. ASAIO J 61(2): 190-5. [Crossref]

9. Lequier L, Horton SB, McMullan DM, Bartlett RH (2013 )Extracorporeal membrane oxygenation circuitry. Pediatr Crit Care Med 14(5 Suppl 1): S7-12. [Crossref]

10. Steinhorn RH, Isham-Schopf B, Smith C, Green TP (1989) Hemolysis during longterm extracorporeal membrane oxygenation. J Pediatr 115(4): 625-30. [Crossref]

11. Skogby M, Mellgren K, Adrian K, Friberg LG, Chevalier JY, Mellgren G (1998) Induced cell trauma during in vitro perfusion: a comparison between two different perfusion systems. Artif Organs 22(12): 1045-51.

12. Rother RP, Bell L, Hillmen P, Gladwin MT (2005) The clinical sequelae of intravascular hemolysis and extracellular plasma hemoglobin: a novel mechanism of human disease. JAMA 293(13): 1653-62. [Crossref]

13. Cappellini MD. (2007)Coagulation in the pathophysiology of hemolytic anemias. Hematology Am Soc Hematol Educ Program 74-8. [Crossref]

14. Vermeulen Windsant IC, Hanssen SJ, Buurman WA, Jacobs MJ (2011) Cardiovascular surgery and organ damage: time to reconsider the role of hemolysis. J Thorac Cardiovasc Surg 142(1): 1-11. [Crossref]

15. Lyu L, Long C, Hei F, Ji B, Liu J, Yu K, et al. (2016) Plasma Free Hemoglobin Is a Predictor of Acute Renal Failure During Adult Venous-Arterial Extracorporeal Membrane Oxygenation Support. J Cardiothorac Vasc Anesth 30(4): 891-5. [Crossref]

16. Neal JR, Quintana E, Pike RB, Hoyer JD, Joyce LD, Schears G (2015) Using Daily Plasma-Free Hemoglobin Levels for Diagnosis of Critical Pump Thrombus in Patients Undergoing ECMO or VAD Support. J Extra Corpor Technol 47(2): 103-8. [Crossref]

17. Lou S, MacLaren G, Best D, Delzoppo C, Butt W (2014) Hemolysis in pediatric patients receiving centrifugal-pump extracorporeal membrane oxygenation: prevalence, risk factors, and outcomes. Crit Care Med 42(5): 1213-20. [Crossref]

18. Gbadegesin R, Zhao S, Charpie J, Brophy PD, Smoyer WE, Lin JJ (2009) Significance of hemolysis on extracorporeal life support after cardiac surgery in children. Pediatr Nephrol 24(3): 589-95. [Crossref]

19. Villa G, Katz N, Ronco C (2015) Extracorporeal Membrane Oxygenation and the Kidney. Cardiorenal Med 6(1): 50-60. [Crossref]

20. Thayyil S, Milligan DW (2006) Single versus double volume exchange transfusion in jaundiced newborn infants. Cochrane Database Syst Rev (4): CD004592. 
21. Merchant RH, Sakhalkar VS, Rajadhyaksha SB (1992) Exchange transfusions via peripheral vessels. Indian Pediatr 29(4): 457-60.

22. Schober PH. (1990) [Automated exchange transfusion in premature and newborn infants with hyperbilirubinemia using a peripheral arteriovenous vascular access device]. Wien Klin Wochenschr 102(16): 471-5. [Crossref]

23. Shakoor A, Svetlana S, Brewer MP, Okochi S, Neunert CE, Cheung EW, et al. (2018) Continuous double volume exchange transfusion is a safe treatment for ECMO-induced hemolysis. Journal of Pediatric Surgery Case Reports 32: 75-8.

24. Boggs TR, Westphal MC (1960) Mortality of Exchange Transfusion. Pediatrics 26(5): 745-55.

25. Kielstein JT, Heiden AM, Beutel G, Gottlieb J, Wiesner O, et al. (2013) Renal function and survival in 200 patients undergoing ECMO therapy. Nephrol Dial Transplant 28(1): 86-90. [Crossref]

26. Elella RA, Habib E, Mokrusova P, Joseph P, Aldalaty H, et al.(2017) Incidence and outcome of acute kidney injury by the pRIFLE criteria for children receiving extracorporeal membrane oxygenation after heart surgery. Ann Saudi Med 37(3): 201-6. [Crossref]

27. Gupta P, Beam B, Schmitz ML. (2015) Outcomes associated with the use of renal replacement therapy in children receiving extracorporeal membrane oxygenation after heart surgery: a multi-institutional analysis. Pediatr Nephrol30(6): 1019-26. [Crossref]

28. Wright E (2004) Therapeutic plasma exchange in children. Paediatr Nurs 16(9): 39-42.

29. Puppe B, Kingdon EJ (2014) Membrane and centrifugal therapeutic plasma exchange: practical difficulties in anticoagulating the extracorporeal circuit. Clin Kidney J7(2): 201-5. [Crossref]

30. Grobety M, Venetz JP, Genton CL, Nicod P (1995) [Malfunction of a mitral bioprosthesis, hemolysis and acute renal insufficiency]. Schweiz Med Wochenschr 125(36): 1679-83. [Crossref]

31. Couzi L, Morel D, Deminiere C, Merville P (2004) An unusual endocarditisinduced crescentic glomerulonephritis treated by plasmapheresis. Clin Nephrol 62(6): 461-4. [Crossref]
32. Hayes C, Shafi H, Mason H, Klapper E (2016) Successful reduction of plasma freehemoglobin using therapeutic plasma exchange: A case report. Transfus Apher Sci 54(2): 253-5. [Crossref]

33. Raval JS, Wearden PD, Orr RA, Kiss JE (2012) Plasma exchange in a 13-year-old male with acute intravascular hemolysis and acute kidney injury after placement of a ventricular assist device. J Clin Apher 27(5): 274-7. [Crossref]

34. Fredlund H, Berseus O, Bjorsell-Ostlilng E, Filbey D(1989) A retrospective study of acute plasma exchange in severe intravascular hemolysis. Eur J Haematol 43(3): 259-61. [Crossref]

35. Hei F, Irou S, Ma J, Long C (2009) Plasma exchange during cardiopulmonary bypass in patients with severe hemolysis in cardiac surgery. ASAIO J 55(1): 78-82. [Crossref]

36. Jhang J, Middlesworth W, Shaw R, Charette K, Papa J, et al. (2007) Therapeutic plasma exchange performed in parallel with extra corporeal membrane oxygenation for antibody mediated rejection after heart transplantation. J Clin Apher 22(6): 333-8. [Crossref]

37. Chong M, Lopez-Magallon AJ, Saenz L, Sharma MS, Althouse AD, et al. (2017) Use of Therapeutic Plasma Exchange during Extracorporeal Life Support in Critically Ill Cardiac Children with Thrombocytopenia-Associated Multi-Organ Failure. Front Pediatr 5: 254. [Crossref]

38. Cortina G, McRae R, Chiletti R, Butt W (2018) Therapeutic Plasma Exchange in Critically Ill Children Requiring Intensive Care. Pediatr Crit Care Med 19(2): e97-e104. [Crossref]

39. Dyer M, Neal MD, Rollins-Raval MA, Raval JS (2014) Simultaneous extracorporeal membrane oxygenation and therapeutic plasma exchange procedures are tolerable in both pediatric and adult patients. Transfusion 54(4): 1158-65. [Crossref]

40. Pan KC, McKenzie DP, Pellegrino V, Murphy D, Butt W. (2016) The meaning of a high plasma free haemoglobin: retrospective review of the prevalence of haemolysis and circuit thrombosis in an adult ECMO centre over 5 years. Perfusion 31(3): 223-31. [Crossref]

41. Peek GJ, Firmin RK (1999) The inflammatory and coagulative response to prolonged extracorporeal membrane oxygenation. ASAIO J 45(4): 250-63. [Crossref]

\section{Citation:}

Aqsa Shakoor, Ariela Zenilman, Jennifer DeFazio, Linda Li, Cindy Neunert, Angela Kadenhe-Chiweshe (2018) Therapeutic Modalities for Management of Hemolysis in Pediatric Extracorporeal Membrane Oxygenation (ECMO). J Clin Res Med Volume 1(3): 1-3. DOI: 10.31038/JCRM.1000106 